\title{
Crystal Structural Investigations for Understanding the Hydrogen Storage Properties of $\mathrm{YMgNi}_{4}$-Based Alloys
}

\author{
Toyoto Sato,* Tomohiro Mochizuki, Kazutaka Ikeda, Takashi Honda, Toshiya Otomo, \\ Hajime Sagayama, Heena Yang, Wen Luo, Loris Lombardo, Andreas Züttel, Shigeyuki Takagi,
} Tatsuoki Kono, and Shin-ichi Orimo

Cite This: ACS Omega 2020, 5, 31192-31198

Read Online

ACCESS | Lلlll Metrics \& More | 回 Article Recommendations | SI Supporting Information

ABSTRACT: The hydrogen storage properties and crystal structures of $\mathrm{YMgNi}_{4}$-based alloys, which were synthesized from $(2-x) \mathrm{YNi}_{2}$ and $x \mathrm{MgNi}_{2}(0.6 \leq x \leq 1.2)$, were investigated by pressure-composition-temperature measurements and powder neutron diffraction at a deuterium gas pressure to understand the hydrogen absorption and desorption reactions viewed from atomic arrangements around $\mathrm{H}$ atoms. Reducing the amounts of $\mathrm{MgNi}_{2}$, which was utilized as a $\mathrm{Mg}$ source in $\mathrm{YMgNi}_{4}$-based alloys, has been observed to lower the hydrogen absorption and desorption pressures and increase the hydrogen storage capacities. However, the reversible hydrogen capacity attained a maximum value of 1.2 mass \% at $x=0.8$ because of the formation of a thermodynamically stable hydride in which hydrogen was not released at $x=0.6$. In the case of $x=0.6$, the

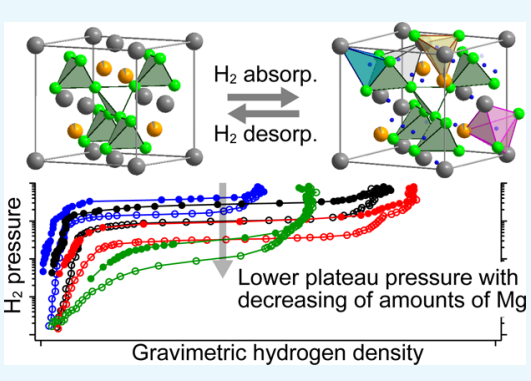
presence of excessive $\mathrm{Y}$ atoms around the $\mathrm{H}$ atoms in the hydrogen-absorbed phase would lead to the formation of a hydride with stronger interaction between $\mathrm{Y}$ and $\mathrm{H}$ because of the affinity between them. Moreover, the presence of small amounts of $\mathrm{D}$ atoms with short interatomic $\mathrm{D}-\mathrm{D}$ distances (1.6 and $1.9 \AA)$ in the deuterium-absorbed phase $\left(\mathrm{Y}_{0.81} \mathrm{Mg}_{1.19} \mathrm{Ni}_{4.00} \mathrm{D}_{3.35}\right.$ and $\left.\mathrm{Y}_{1.06} \mathrm{Mg}_{0.94} \mathrm{Ni}_{4.00} \mathrm{D}_{3.86}\right)$ at $<5 \mathrm{MPa}$ and $323 \mathrm{~K}$ was proposed by the crystal structural investigations. The $\mathrm{D}$ atoms with short $\mathrm{D}-\mathrm{D}$ interatomic distances were located in the same local atomic arrangements of $\mathrm{D}$ atoms in a deuterium-absorbed phase, which were formed at a higher-pressure range, and had higher hydrogen storage capacities than the deuterium-absorbed phases in this study.

\section{INTRODUCTION}

Hydrogen is a promising renewable energy carrier. Thus, it is necessary to develop efficient hydrogen storage technologies. Several approaches involving compressed $\mathrm{H}_{2}$ gas or liquid $\mathrm{H}_{2}$ as well as material-based storage, e.g., utilizing metal hydrides, have been proposed. In these methods, metal hydrides are used to store hydrogen with high gravimetric and volumetric hydrogen densities at moderate pressures and temperatures compared with compressed $\mathrm{H}_{2}$ gas and liquid $\mathrm{H}_{2}{ }^{1,2}$ To date, numerous metal hydrides have been reported as potential hydrogen storage materials. Among them, $\mathrm{Mg}$, which is an abundant and light element, reacts with $\mathrm{H}_{2}$ to form $\mathrm{MgH}_{2}$ with high gravimetric and volumetric hydrogen densities, 7.7 mass $\%$ and $109 \mathrm{kgH}_{2} / \mathrm{m}^{3}$, respectively. Therefore, $\mathrm{Mg}$ has been shown as a particularly promising metal for hydrogen storage. Although $\mathrm{MgH}_{2}$ has high hydrogen storage capacities, the thermodynamic stabilities and kinetics of hydrogen absorption and desorption reactions (e.g., enthalpy $=-74 \mathrm{~kJ} / \mathrm{mol} \mathrm{H}_{2}$ ) are not suitable for the utilization of $\mathrm{Mg}$ as a hydrogen storage material. ${ }^{3}$ Higher thermodynamic stabilities would relate to the ionic bonding in $\mathrm{MgH}_{2}$ that is composed of $\mathrm{Mg}^{2+}$ and $\mathrm{H}^{-}$. To improve the thermodynamic stability, the development of $\mathrm{Mg}$ alloys with transition metals, such as $\mathrm{Ni}$, can be an effective approach. For example, $\mathrm{RE}_{(2-x)} \mathrm{Mg}_{x} \mathrm{Ni}_{4}$ (RE: rare-earth element, $0<x<2$ ) has been applied to reversible hydrogen absorption and desorption reactions at ambient temperature. ${ }^{4-11}$ In the case of $\mathrm{RE}_{(2-x)} \mathrm{Mg}_{x} \mathrm{Ni}_{4}$, the $\mathrm{H}$ atom is in the elemental state, which is qualitatively associated with less interaction between the metal elements and $\mathrm{H}$ than $\mathrm{MgH}_{2}$. Then, the subsequent hydrogen absorption reaction steps of $\mathrm{LaMgNi}_{4}$ at $373 \mathrm{~K}$ in a hydrogen (deuterium) atmosphere have been reported ${ }^{6}$

$$
\begin{aligned}
& \mathrm{LaMgNi}_{4}+0.38 \mathrm{H}_{2}(\mathrm{~g}) \\
& \quad \rightarrow \mathrm{LaMgNi}_{4} \mathrm{H}_{0.75} \text { at a hydrogen gas pressure of } 0.5 \mathrm{MPa}
\end{aligned}
$$

$$
\begin{aligned}
& \mathrm{LaMgNi}_{4} \mathrm{H}_{0.75}+1.48 \mathrm{H}_{2}(\mathrm{~g}) \\
& \quad \rightarrow \mathrm{LaMgNi}_{4} \mathrm{H}_{3.70} \text { at a hydrogen gas pressure of } 1.0 \mathrm{MPa}
\end{aligned}
$$

Received: September 16, 2020

Accepted: November 16, 2020

Published: November 30, 2020 


$$
\begin{aligned}
& \mathrm{LaMgNi}_{4} \mathrm{H}_{3.70}+0.58 \mathrm{H}_{2}(\mathrm{~g}) \\
& \quad \rightarrow \mathrm{LaMgNi}_{4} \mathrm{H}_{4.85} \text { at a hydrogen gas pressure of } 5.2 \mathrm{MPa}
\end{aligned}
$$

Figure 1 shows the crystal structures of $\mathrm{LaMgNi}_{4}$ obtained during the hydrogen absorption reaction. ${ }^{6,10}$

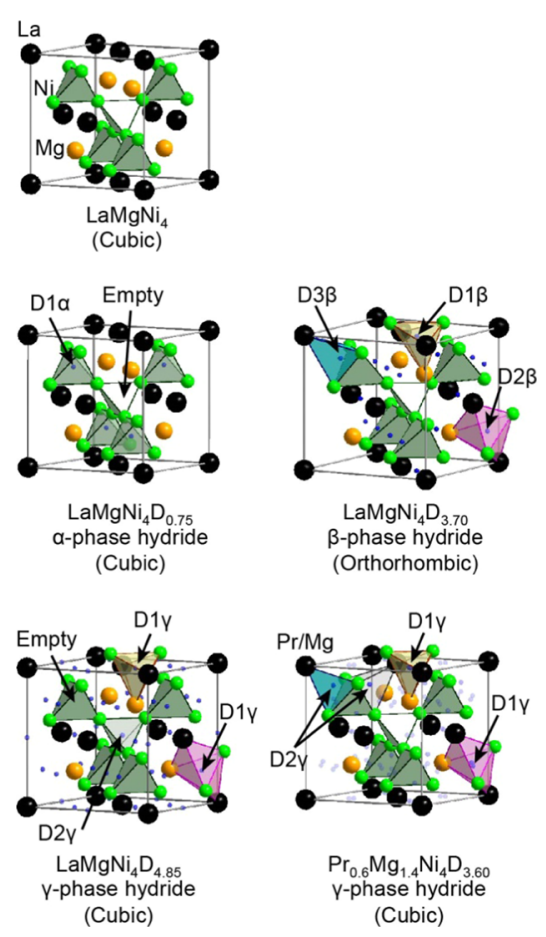

Figure 1. Crystal structures of $\mathrm{REMgNi}_{4}$, the $\alpha$-phase hydride $\left(\mathrm{LaMgNi}_{4} \mathrm{H}_{0.75}\right.$ in the space group $\bar{F} \overline{4} 3 \mathrm{~m}$ (No. 216)), the $\beta$-phase hydride $\left(\mathrm{LaMgNi}_{4} \mathrm{H}_{3.70}\right.$ in the space group $\mathrm{Pmn}_{1}$ (No. 31)), and the $\gamma$-phase hydride $\left(\mathrm{LaMgNi}_{4} \mathrm{H}_{4.85}\right.$ in the space group $\bar{F} \overline{4} 3 m$ (No. 216)). The $\beta$-phase hydride exhibits similar metal atomic arrangements to the alloy, $\alpha$-phase, or $\gamma$-phase hydrides. Two crystal structures are illustrated for the $\gamma$-phase hydride: $\mathrm{LaMgNi}_{4} \mathrm{D}_{4.85}$, in which the $\mathrm{D}$ atoms $(\mathrm{D} 1 \gamma$ and $\mathrm{D} 2 \gamma)$ are located at $24 g(0.987,0.25,0.25)$ and $4 b$ $(0.5,0.5,0.5)$ in the space group $F \overline{4} 3 m$ (No. 216), and $\mathrm{Pr}_{0.6} \mathrm{Mg}_{1.4} \mathrm{Ni}_{4.0} \mathrm{D}_{3.6}$, in which $\mathrm{Pr}$ and some of the $\mathrm{Mg}$ atoms coexist at $4 a(0,0,0)$, whereas the $\mathrm{D}$ atoms $(\mathrm{D} 1 \gamma$ and $\mathrm{D} 2 \gamma)$ are located at $48 h$ $(0.7363,0.7363,0.9979)$ and $16 e(0.8493,0.8493,0.8493)$ in the space group $\bar{F} \overline{4} 3 m$ (No. 216).

As it can be seen, $\mathrm{LaMgNi}_{4}$ adopted a face-centered cubic (FCC) $A_{u B e}$-type crystal structure, which resembles the structure of the C15-type Laves phase alloy (a $\mathrm{MgCu}_{2}$-type crystal structure). Neutron diffraction experiments at deuterium gas pressure revealed the initial formation of $\mathrm{LaMgNi}_{4} \mathrm{D}_{0.75}$ (gravimetric hydrogen density: 0.2 mass \%), which adopted an FCC crystal structure while maintaining the Bravais lattice of $\mathrm{LaMgNi}_{4}$, referred to as the $\alpha$-phase hydride in this study. ${ }^{6}$ It was shown that the $\mathrm{D}$ atoms (D1 $\left.\alpha\right)$ were located at the tetrahedral sites and coordinated by four $\mathrm{Ni}$ atoms. In the second step, $\mathrm{LaMgNi}_{4} \mathrm{D}_{3.70}$ (gravimetric hydrogen density: 0.9 mass \%) with a primitive orthorhombic crystal structure, which we refer to as the $\beta$-phase hydride in this study, was formed. In this crystal structure, the $\mathrm{D}$ atoms (D1 $\beta$ and $\mathrm{D} 2 \beta$ ) were located inside of the triangular bipyramid and coordinated by two $\mathrm{La}$, one $\mathrm{Mg}$, and two $\mathrm{Ni}$ atoms. The remaining $\mathrm{D}$ atoms (D3 $\beta$ ) were positioned inside of the tetrahedron and coordinated by one $\mathrm{La}$ and three $\mathrm{Ni}$ atoms.
Furthermore, in the third step, $\mathrm{LaMgNi}_{4} \mathrm{D}_{4.85}$ (gravimetric hydrogen density: 1.2 mass \%) with an FCC crystal structure, which we refer to as the $\gamma$-phase hydride in this paper, was formed. The $\mathrm{D}$ atoms $(\mathrm{D} 1 \gamma)$ were located inside of the triangular bipyramid and coordinated by two $\mathrm{La}$, one $\mathrm{Mg}$, and two $\mathrm{Ni}$ atoms. The remaining $\mathrm{D}$ atoms (D2 $\gamma)$ in the crystal structure were positioned inside of the tetrahedron and coordinated by four $\mathrm{Ni}$ atoms. In the case of $\operatorname{Pr}_{0.6} \mathrm{Mg}_{1.4} \mathrm{Ni}_{4}$ $\left(\mathrm{Pr}_{0.6} \mathrm{Mg}_{1.4} \mathrm{Ni}_{4} \mathrm{D}_{3.6}\right.$, gravimetric hydrogen density: 0.9 mass \%), it has been reported that the $\mathrm{D} 2 \gamma$ positions in the $\gamma$-phase hydride differed from those in the $\gamma$-phase hydride, $\mathrm{LaMgNi}_{4} \mathrm{D}_{4.85}$ (Figure 1). ${ }^{10}$

Since $\mathrm{Y}$ is the lightest $\mathrm{RE}$ in $\mathrm{REMgNi}_{4}, \mathrm{YMgNi}_{4}$ was expected to have a higher gravimetric hydrogen density than the other $\mathrm{REMgNi}_{4}$ because it has the lightest formula weight. By contrast, the hydrogen storage reaction was halted during the formation of the $\beta$-phase hydride, whose gravimetric hydrogen density is comparable to that of $\mathrm{REMgNi}_{4}$ (approximately 1.0 mass \%) containing heavier RE elements. ${ }^{7,11}$ Although the $\gamma$-phase hydride was typically obtained at a higher hydrogen pressure, the reaction pressure and pathways depended on the RE elements or the compositional ratios of $\mathrm{RE}$ to $\mathrm{Mg}$. This indicated that if the compositional ratios of $\mathrm{Y}$ to $\mathrm{Mg}$ could be optimized, $\mathrm{YMgNi}_{4}$ would be able to form hydrides with more hydrogen atoms. Additionally, this implied that the reactions were related to the interactions between the metal elements and $\mathrm{H}$ (affinities of the metal elements toward $\mathrm{H}$ ) in the crystal structures. However, the roles of $\mathrm{RE}$ and $\mathrm{Mg}$ in $\mathrm{REMgNi}_{4}$-based alloys in hydrogen absorption and desorption reactions have not been understood properly. Hence, in this study, we attempted the synthesis of $\mathrm{YMgNi}_{4}$-based alloys exhibiting systematically adjusted compositional ratios of $\mathrm{Y}$ to $\mathrm{Mg}$ and studied their crystal structures to understand the local atomic arrangements around the $\mathrm{H}$ atoms. On the basis of the investigation of the atomic arrangements, we aimed to improve the gravimetric hydrogen densities and understand the roles of $\mathrm{Y}$ and $\mathrm{Mg}$ in $\mathrm{YMgNi}_{4}$ as well as in other $\mathrm{REMgNi}_{4}$-based alloys that are used for hydrogen storage.

\section{RESULTS AND DISCUSSION}

Synthesis. Figure 2 shows the powder X-ray diffraction (PXD) patterns of the as-synthesized materials. Although small amounts of $\mathrm{Y}_{2} \mathrm{O}_{3}$ and $(\mathrm{Y}, \mathrm{Mg}) \mathrm{Ni}_{3}$ were identified after the synthesis, the main Bragg peaks were indexed by an FCC unit cell with $a=6.9-7.1$ (Table 1).

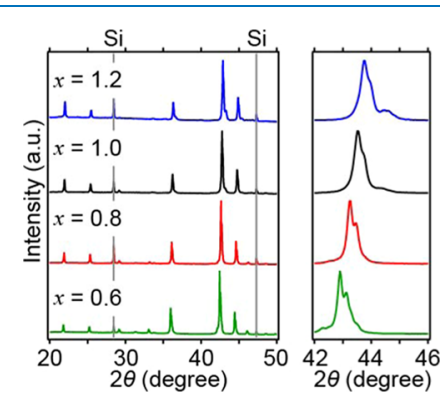

Figure 2. PXD patterns of $(2-x) \mathrm{YNi}_{2}+x \mathrm{MgNi}_{2}$ after the syntheses. The $\mathrm{Si}$ powder was added as an internal standard to correct the Bragg peak positions. The blue, black, red, and green lines correspond to $x=$ $1.2,1.0,0.8$, and 0.6 . 
Table 1. Unit Cell Parameters after the Syntheses and Pressure-Composition-Temperature (PCT) Measurements at $323 \mathrm{~K}^{a}$

\begin{tabular}{cccc} 
& \multicolumn{2}{c}{ unit cell parameter $a(\AA)$} & \\
\cline { 2 - 3 }$(2-x) \mathrm{YNi}_{2}+x \mathrm{MgNi}_{2}$ & $\begin{array}{c}\text { as- } \\
\text { synthesized }\end{array}$ & $\begin{array}{c}\text { after PCT } \\
\text { measurement }\end{array}$ & $\begin{array}{c}\text { refined } \\
\text { composition }\end{array}$ \\
$x=1.2$ & $6.9888(4)$ & $6.9856(07)$ & $\mathrm{Y}_{0.78} \mathrm{Mg}_{1.22} \mathrm{Ni}_{4.00}$ \\
$x=1.0$ & $7.0066(3)$ & $7.0072(22)$ & $\mathrm{Y}_{0.81} \mathrm{Mg}_{1.19} \mathrm{Ni}_{4.00}$ \\
$x=0.8$ & $7.0297(2)$ & $7.0308(26)$ & $\mathrm{Y}_{1.06} \mathrm{Mg}_{0.94} \mathrm{Ni}_{4.00}$ \\
$x=0.6$ & $7.0572(2)$ & $7.0680(14)$ & $\mathrm{Y}_{1.16} \mathrm{Mg}_{0.84} \mathrm{Ni}_{4.00}$
\end{tabular}

${ }^{a_{T}}$ The data include the refined composition of the main phase of $(2-$ $x) \mathrm{YNi}_{2}+x \mathrm{MgNi}_{2}$. The unit cell parameters were obtained from PXD, whose Bragg peak positions were corrected by $\mathrm{Si}$ as the internal standard. The refined compositions were obtained from the Rietveld method on the synchrotron radiation powder X-ray diffraction (SRPXD) data.

The unit cell parameter decreased with an increasing amount of $\mathrm{MgNi}_{2}$, which was the source of $\mathrm{Mg}$ in the $\mathrm{YMgNi}_{4}$-based alloys. $\mathrm{YMgNi}_{4}$ with a Y:Mg ratio of $1: 1$ has been previously evaluated. ${ }^{4,11,12}$ Nevertheless, the reported unit cell parameters (refs 4, 11, and 12) are inconsistent. The discrepancies probably originated from correction methods of the Bragg peak positions in PXD in refs 4 and 11 or from the partial replacement of the $\mathrm{Mg}$ atoms with the $\mathrm{Y}$ one and vice versa (ref 12). In this study, the chemical compositions of the final products were refined from those of the starting materials by the Rietveld method using the SR-PXD data obtained at room temperature. The established chemical compositions are summarized in Table 1. The Rietveld refinement fits (Figures S1-S4) and crystallographic parameters (Tables S1-S4) are presented in the Supporting Information. The observed SRPXD data of all of the samples were reasonably reproduced by an FCC structure. The inconsistencies in the quantity of $\mathrm{Mg}$ between the ratios of the starting materials and final products were suspected to be due to impurities in the starting materials or the evaporation of $\mathrm{Mg}$ during the syntheses. However, the overall trend of the quantities of $\mathrm{Mg}$ in the final products is consistent with the ratios of the starting materials.

Hydrogen Storage Properties. Figure 3 shows the PCT curves of $\mathrm{YMgNi}_{4}$-based alloys at $323 \mathrm{~K}$. The PCT curves were obtained after several hydrogen absorption and desorption reactions at $323 \mathrm{~K}$. Table 2 lists the equilibrium pressures of the hydrogen absorption and desorption, i.e., the plateau pressures, as well as the hydrogen storage capacities.

The regions of the plateau pressure on the curves correspond to the hydrogen absorption that is due to the formation of the $\beta$-phase hydride, which was confirmed by powder neutron diffraction (PND). A decrease in the amounts of $\mathrm{Mg}$ resulted in lowered hydrogen absorption and desorption pressures and increased hydrogen storage capacities. By contrast, the maximum hydrogen storage capacity reached 1.2 mass $\%$ at $x=0.8$. Moreover, the unit cell parameters and PXD patterns after the PCT measurements were listed (Table 1). It was observed that the unit cell parameter of the $\mathrm{YMgNi}_{4}$ based alloy with $x=0.6$ did not return to the initial value after the PCT measurement. Furthermore, in the hydrogen absorption involving $\mathrm{LaMgNi}_{4}$ (eqs 1-3), the $\alpha$-phase hydride displayed an FCC lattice, which was maintained from the initial alloy. Hence, the unit cell parameter at $x=0.6$ suggested the formation of the $\alpha$-phase hydride. In the first hydrogen absorption reaction at $x=0.6$, the hydrogen capacity was

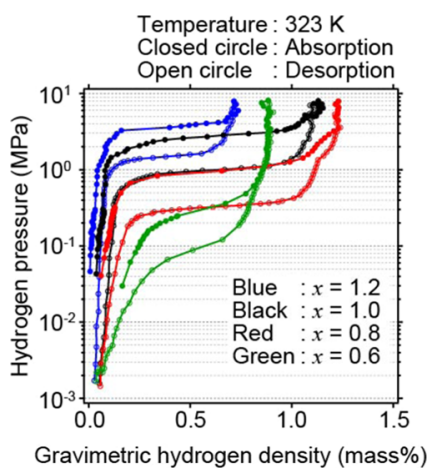

Figure 3. PCT curves of $(2-x) \mathrm{YNi}_{2}+x \mathrm{MgNi}_{2}$ at $323 \mathrm{~K}$. Using the sample with $x=1.0$, the cycle degradation was confirmed up to five cycles after exhibiting stability from the second to fifth cycles. The sample with $x=1.0$ featured the fifth hydrogen absorption and desorption reaction cycles. Except for $x=1.0$, the third hydrogen absorption and desorption reaction cycles are plotted. The blue, black, red, and green circles correspond to $x=1.2,1.0,0.8$, and 0.6. The closed and open circles indicate the hydrogen absorption and desorption reactions, respectively.

Table 2. Equilibrium Pressures for Hydrogen Absorption and Desorption Reactions and Hydrogen Storage Capacities of $(2-x) \mathrm{YNi}_{2}+x \mathrm{MgNi}_{2}$ at $323 \mathrm{~K}$

\begin{tabular}{|c|c|c|c|}
\hline \multirow[b]{2}{*}{$(2-x) \mathrm{YNi}_{2}+x \mathrm{MgNi}_{2}$} & \multicolumn{2}{|c|}{$\begin{array}{l}\text { equilibrium pressure } \\
(\mathrm{MPa})\end{array}$} & \multirow{2}{*}{$\begin{array}{l}\text { gravimetric hydrogen } \\
\text { density (mass \%) }\end{array}$} \\
\hline & absorption & desorption & \\
\hline$x=1.2$ & 3.74 & 1.48 & 0.73 \\
\hline$x=1.0$ & 2.71 & 1.00 & 1.14 \\
\hline$x=0.8$ & 0.99 & 0.33 & 1.23 \\
\hline$x=0.6$ & 0.34 & 0.10 & 0.86 \\
\hline
\end{tabular}

comparable to that at $x=0.8$. However, after the second cycle, the hydrogen capacity at $x=0.6$ was lower than that at $x=0.8$. This indicated that the $\alpha$-phase hydride was thermodynamically too stable to release hydrogen at $323 \mathrm{~K}$. Furthermore, a decreased crystallinity with decreasing amounts of $\mathrm{Mg}$ was observed after the PCT measurement (Figure S5 in the Supporting Information). It was attributed to the radius ratios of the $\mathrm{Y}, \mathrm{Mg}$, and $\mathrm{Ni}$ atoms, similarly to the Laves phase hydrides reported by $\mathrm{K}$. Aoki et al. ${ }^{13}$ Although the ratios of $\mathrm{Y}$ and $\mathrm{Mg}$ affected the control of hydrogen storage capacities and plateau pressures, lower amounts of $\mathrm{Mg}$ and an excessive amount of Y caused the formation of the thermodynamically stable $\alpha$-phase hydride. The $\alpha$-phase hydride resulted in decreased hydrogen storage capacities after the second cycle and reduced crystallinity. The hydrogen storage properties are discussed in the next section based on the atomic arrangements. At $x=0.8$, hydrogen absorption was observed at a gravimetric hydrogen density of ca. 1.0-1.2 mass \% and above $1.0 \mathrm{MPa}$ at $323 \mathrm{~K}$ (Figure 3 ). This reaction might be a transformation from the $\beta$ - to the $\gamma$-phase hydride.

Since the material with $x=0.8$ exhibited the highest hydrogen storage capacity in this study, the PCT measurements were performed at 303-343 K (Figure S6 in the Supporting Information) to obtain the thermodynamic parameters, specifically enthalpy $(\Delta H)$ and entropy $(\Delta S)$, of the hydrogen absorption and desorption. Table 3 summarizes the $\Delta H$ and $\Delta S$ values. Notably, $\Delta H$ of the analyzed material 
was comparable to that of a hydrogen storage alloy $\left(\mathrm{LaNi}_{5}\right)$ $\left(\Delta H \approx-30 \mathrm{~kJ} / \mathrm{mol} \mathrm{H}_{2}\right){ }^{14}$

Table 3. Thermodynamic Parameters $(\Delta H$ and $\Delta S)$ of Hydrogen Absorption and Desorption on $1.2 \mathrm{YNi}_{2}+$ $0.8 \mathrm{MgNi}_{2}$

\begin{tabular}{lcc} 
& absorption & desorption \\
\hline enthalpy $\Delta H\left(\mathrm{~kJ} / \mathrm{mol} \mathrm{H}_{2}\right)$ & -29.2 & -35.1 \\
entropy $\Delta S\left(\mathrm{~J} / \mathrm{mol} \mathrm{H}_{2} \mathrm{~K}\right)$ & 110.5 & 119.8
\end{tabular}

\section{Atomic Arrangements during Hydrogen Absorption.}

The crystal structures of $\mathrm{Y}_{0.81} \mathrm{Mg}_{1.19} \mathrm{Ni}_{4.00}\left(1.0 \mathrm{YNi}_{2}+\right.$ $\left.1.0 \mathrm{MgNi}_{2}\right)$ and $\mathrm{Y}_{1.06} \mathrm{Mg}_{0.94} \mathrm{Ni}_{4.00}\left(1.2 \mathrm{YNi}_{2}+0.8 \mathrm{MgNi}_{2}\right)$ during hydrogen absorption were investigated by $\mathrm{PND}$ in vacuum and at a deuterium gas pressure of 3-5 $\mathrm{MPa}$ at $323 \mathrm{~K}$. Figure 4
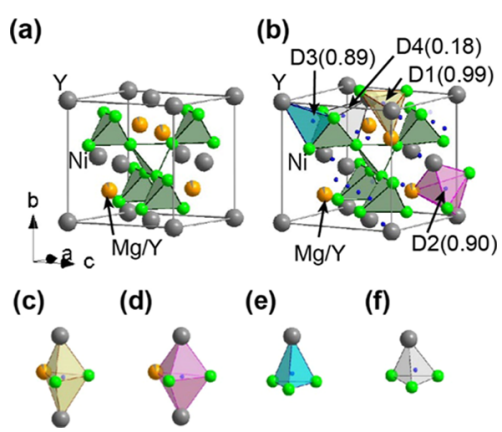

Figure 4. Crystal structures of (a) $\mathrm{Y}_{1.06} \mathrm{Mg}_{0.94} \mathrm{Ni}_{4.00}$ and (b) $\mathrm{Y}_{1.06} \mathrm{Mg}_{0.94} \mathrm{Ni}_{4.00} \mathrm{D}_{3.86}$, and the $(\mathrm{c}-\mathrm{f})$ local atomic arrangements around the $\mathrm{D}$ atoms. The $\mathrm{Y}, \mathrm{Mg}, \mathrm{Ni}$, and $\mathrm{D}$ atoms are represented by the gray, orange, green, and blue circles, respectively. In the crystal structures, the corner-shared tetrahedra formed by four $\mathrm{Ni}$ atoms are represented as the green polyhedra. The gray lines connect the $\mathrm{Y}$ atoms in $\mathrm{Y}_{1.06} \mathrm{Mg}_{0.94} \mathrm{Ni}_{4.00} \mathrm{D}_{3.86}$ to compare it with the unit cell of $\mathrm{Y}_{1.06} \mathrm{Mg}_{0.94} \mathrm{Ni}_{4.00}$. In the local atomic arrangements around the $\mathrm{D}$ atoms, the hydrogen sites in the triangular bipyramid and tetrahedra are represented as pink (D1), yellow (D2), cyan (D3), and green (D4) polyhedra.

shows the crystal structures and local atomic arrangements around the $\mathrm{D}$ atoms in $\mathrm{Y}_{1.06} \mathrm{Mg}_{0.94} \mathrm{Ni}_{4.00} \mathrm{D}_{3.86}$ only since the crystal structure of $\mathrm{Y}_{0.81} \mathrm{Mg}_{1.19} \mathrm{Ni}_{4.00} \mathrm{D}_{3.35}$ fundamentally exhibited the same atomic arrangements with $\mathrm{Y}_{1.06} \mathrm{Mg}_{0.94} \mathrm{Ni}_{4.00} \mathrm{D}_{3.86}$ with different site occupancies. The Rietveld refinement fit of the PND pattern for the $1.2 \mathrm{YNi}_{2}+$ $0.8 \mathrm{MgNi}_{2}$ under a $\mathrm{D}_{2}$ pressure of $3 \mathrm{MPa}$ is shown in Figure 5; the Rietveld refinement fit of the PND patterns for $1.0 \mathrm{YNi}_{2}+$ $1.0 \mathrm{MgNi}_{2}$ under vacuum and $\mathrm{D}_{2}$ pressure of $5 \mathrm{MPa}$ and that for $1.2 \mathrm{YNi}_{2}+0.8 \mathrm{MgNi}_{2}$ under vacuum are shown in Figures S7-S9 in the Supporting Information; and the crystallographic parameters of the main phases are listed in Tables S5-S10 in the Supporting information. Based on the crystal structural investigations, the $\beta$-phase hydrides (deuterides) with orthorhombic unit cells with $a=5.0274(2) \AA, b=5.3823(2)$ $\AA, c=7.2853(3) \AA, V=197.13(1) \AA^{3}$, and $Z=2$ in $P m n 2_{1}$ (No. 31) in $\mathrm{Y}_{0.81} \mathrm{Mg}_{1.19} \mathrm{Ni}_{4.00} \mathrm{D}_{3.35}$ and $a=5.0407(1) \AA, b=$ 5.4162(2) $\AA, c=7.3035(2) \AA, V=199.39(1) \AA^{3}$, and $Z=2$ in $P m n 2_{1}$ (No. 31) in $\mathrm{Y}_{1.06} \mathrm{Mg}_{0.94} \mathrm{Ni}_{4.00} \mathrm{D}_{3.86}$ were observed. The chemical compositions of the deuterides were established as $\mathrm{Y}_{0.81} \mathrm{Mg}_{1.19} \mathrm{Ni}_{4.00} \mathrm{D}_{3.35}$ and $\mathrm{Y}_{1.06} \mathrm{Mg}_{0.94} \mathrm{Ni}_{4.00} \mathrm{D}_{3.86}$, which are consistent with the results obtained from the PCT measurements.
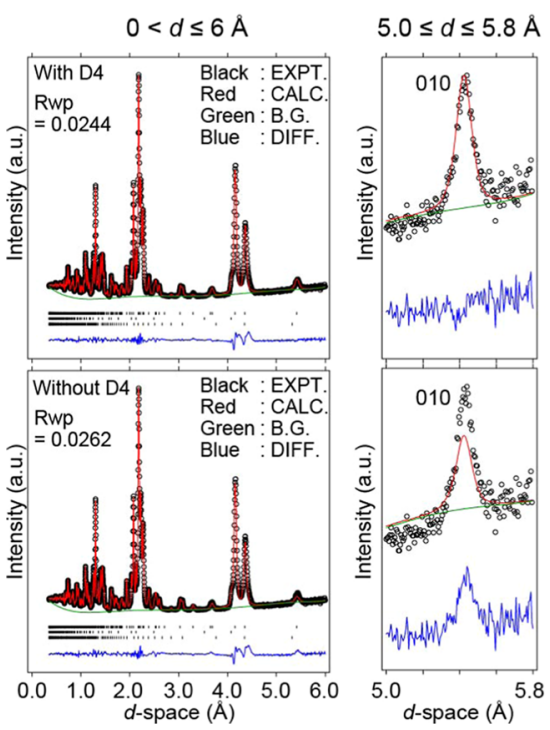

$5.0 \leq d \leq 5.8 \AA$
(Simulated PND)

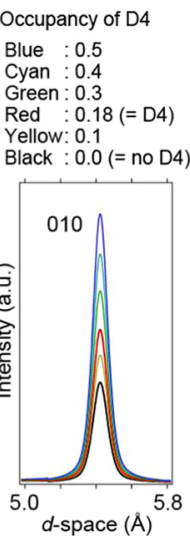

Figure 5. Rietveld refinement fits of the PND for $1.2 \mathrm{YNi}_{2}+0.8 \mathrm{MgNi}_{2}$ at (left) $0<d \leq 6.0 \AA$, (middle) $5 \leq d \leq 5.8 \AA$ under $\mathrm{D}_{2}$ pressure of 3 $\mathrm{MPa}$ at $323 \mathrm{~K}$, and (right) simulated PND patterns from hypothetical crystal structure models based on $\mathrm{Y}_{1.06} \mathrm{Mg}_{0.94} \mathrm{Ni}_{4.00} \mathrm{D}_{3.86}$ with different occupancies of the D4 atoms. The top and bottom profiles are a crystal structure model with and without D4, respectively. In the Rietveld refinement fits, the observed, calculated background and difference between observed and calculated patterns are indicated by circles, red, green, and blue lines, respectively. The positions of Bragg reflection are shown for (top) $\mathrm{Y}_{1.06} \mathrm{Mg}_{0.94} \mathrm{Ni}_{4.00} \mathrm{D}_{3.86}$ (91 wt \%), (middle) $\mathrm{Y}_{1.06} \mathrm{Mg}_{0.94} \mathrm{Ni}_{4.00}$ (5 wt \%), and (bottom) $\mathrm{Y}_{2} \mathrm{O}_{3}$ (4 wt \%). In the simulated PND pattern, occupancies of the D4 atoms with 0.0, $0.1,0.18,0.3,0.4$, and 0.5 are represented by black, yellow, red, green, cyan, and blue lines, respectively. The occupancies of the $\mathrm{D} 4$ atoms with 0.0 , and 0.18 indicate $\mathrm{Y}_{1.06} \mathrm{Mg}_{0.94} \mathrm{Ni}_{4.00} \mathrm{D}_{3.86}$ without and with the D4 atoms, respectively.

The crystal structural investigations revealed that the $D$ atoms were located in four crystallographically different sites, D1, D2, D3, and D4. The D1 and D2 atoms were located inside of the triangular bipyramids and coordinated by two $\mathrm{Y}$, one $\mathrm{Mg}$, and two $\mathrm{Ni}$ atoms. The D3 atoms were positioned inside of the tetrahedron and coordinated by one $\mathrm{Y}$ and three $\mathrm{Ni}$ atoms. Although the positions of D1, D2, and D3 were analogous to those previously reported for the $\beta$-phase hydrides of $\mathrm{REMgNi}_{4}(\mathrm{D} 1 \beta, \mathrm{D} 2 \beta$, and $\mathrm{D} 3 \beta)$, small amounts of $\mathrm{D} 4$ atoms, which were located inside of the tetrahedron and coordinated by one $\mathrm{Y}$ and three $\mathrm{Ni}$ atoms, were identified in our crystal structural investigations (Figure 1).

First, we discuss about the D4 atoms. It is noteworthy that the presence of the D4 atoms in the $\beta$-phase hydrides has not been previously reported for $\mathrm{REMgNi}_{4}$-based alloys $(\mathrm{RE}=$ lanthanides). The crystal structure model of $\mathrm{Y}_{1.06} \mathrm{Mg}_{0.94} \mathrm{Ni}_{4.00} \mathrm{D}_{3.86}$ containing the $\mathrm{D} 4$ atoms exhibited better reproducibility of the experimentally observed PND pattern than the crystal structure model without the D4 atoms (Figure 5 ). The crystal structure models of $\mathrm{Y}_{0.81} \mathrm{Mg}_{1.19} \mathrm{Ni}_{4.00} \mathrm{D}_{3.35}$ with and without the D4 atoms demonstrated comparable fitting to the experimentally observed PND pattern (Figure S8 in the Supporting Information) due to less occupancies of the D4 atoms (0.09). In the Rietveld refinement fit of the PND pattern for $1.2 \mathrm{YNi}_{2}+0.8 \mathrm{MgNi}_{2}$ under a $\mathrm{D}_{2}$ pressure of $3 \mathrm{MPa}$ $\left(\mathrm{Y}_{1.06} \mathrm{Mg}_{0.94} \mathrm{Ni}_{4.00} \mathrm{D}_{3.86}\right)$, the fitting of the (010) reflection observed at $d \approx 5.4 \AA$ clearly revealed the improvement. In simulated PND patterns obtained from hypothetical crystal 
structure models based on $\mathrm{Y}_{1.06} \mathrm{Mg}_{0.94} \mathrm{Ni}_{4.00} \mathrm{D}_{3.86}$ with different occupancies of the D4 atoms (Figure 5), the Bragg peak intensities of the (010) reflection became stronger with increasing $\mathrm{D} 4$ atomic occupancies. This is consistent with the improvement fitting of the (010) reflection on the crystal structure model of $\mathrm{Y}_{1.06} \mathrm{Mg}_{0.94} \mathrm{Ni}_{4.00} \mathrm{D}_{3.86}$ with $\mathrm{D} 4$ atoms. Though the better Rietveld refinement fits of the PND for $\mathrm{Y}_{1.06} \mathrm{Mg}_{0.94} \mathrm{Ni}_{4.00} \mathrm{D}_{3.86}$ were obtained by the $\mathrm{D} 4$ atoms, the interatomic distances between the D4 and the D2 (1.62 $\AA$ ) or the D3 (1.87 $\AA$ ) atoms were shorter than a criterion reported by Switendick, ${ }^{15}$ in which the minimum interatomic $D-D$ distance should be $2.1 \AA$. The interatomic distances of the $\mathrm{D}$ atoms are listed in Table S11 in the Supporting Information. Shorter interatomic D-D distances than the criterion have been often reported for intermetallic compounds. ${ }^{10,16-18}$ Recently, the shortest $\mathrm{H}-\mathrm{H}$ interatomic distances with 1.5$1.6 \AA$ in C15-type Laves-phase alloy, $\mathrm{ZrV}_{2}\left(\mathrm{ZrV}_{2} \mathrm{H}_{3.7}\right)$, were reported by Borgschulte et al. who investigated the $\mathrm{H}$ atomic positions in $\mathrm{ZrV}_{2} \mathrm{H}_{3.7}$ by inelastic neutron scattering combined with theoretical calculations. ${ }^{18}$ In this study, $\mathrm{Y}_{1.06} \mathrm{Mg}_{0.94} \mathrm{Ni}_{4.00}$ adopted similar arrangements to $\mathrm{ZrV}_{2}$, as mentioned in the description of the crystal structure of $\mathrm{REMgNi}_{4}$ in the Introduction section. Notably, the local atomic arrangements of the $\mathrm{D} 4$ atoms in $\mathrm{Y}_{1.06} \mathrm{Mg}_{0.94} \mathrm{Ni}_{4.00} \mathrm{D}_{3.86}$ corresponded to some atomic positions of $\mathrm{D} 2 \gamma$ with short $\mathrm{D}-\mathrm{D}$ interatomic distances $(1.40-1.60 \AA)$ in the $\gamma$-phase hydride $\operatorname{Pr}_{0.6} \mathrm{Mg}_{1.4} \mathrm{Ni}_{4} \mathrm{D}_{3.6}$ (Figure 1), ${ }^{10}$ although $\mathrm{Y}_{1.06} \mathrm{Mg}_{0.94} \mathrm{Ni}_{4.00} \mathrm{D}_{3.86}$ were the $\beta$-phase hydrides. Since powder neutron (or X-ray) diffraction provides averaged atomic arrangements, the D4-D2 or D4-D3 atomic pairs with the short interatomic distances might not simultaneously exist at each atomic site in $\mathrm{Y}_{1.06} \mathrm{Mg}_{0.94} \mathrm{Ni}_{4.00} \mathrm{D}_{3.86}$ (the $\beta$-phase hydride). Considering similarities to $\mathrm{ZrV}_{2} \mathrm{H}_{3.7}$ and $\operatorname{Pr}_{0.6} \mathrm{Mg}_{1.4} \mathrm{Ni}_{4} \mathrm{D}_{3.6} \quad(\gamma$-phase hydride) and better Rietveld fits with $\mathrm{D} 4$ atoms, we propose the presence of the D4 atoms in the averaged crystal structure of the $\beta$-phase hydride, $\mathrm{Y}_{0.81} \mathrm{Mg}_{1.19} \mathrm{Ni}_{4.00} \mathrm{D}_{3.35}$ and $\mathrm{Y}_{1.06} \mathrm{Mg}_{0.94} \mathrm{Ni}_{4.00} \mathrm{D}_{3.86}$.

Next, we discuss the hydrogen storage properties of the $\mathrm{YMgNi}_{4}$-based alloys from the viewpoint of their atomic arrangements and the affinities of metal elements toward the $\mathrm{D}$ atoms. In $\mathrm{Y}_{0.81} \mathrm{Mg}_{1.19} \mathrm{Ni}_{4.00} \mathrm{D}_{3.35}$, excessive $\mathrm{Mg}$ atoms were in the $\mathrm{Y}$ atomic sites. Moreover, in $\mathrm{Y}_{1.06} \mathrm{Mg}_{0.94} \mathrm{Ni}_{4.00} \mathrm{D}_{3.86}$, excessive $\mathrm{Y}$ atoms were located in the $\mathrm{Mg}$ atomic sites. As shown in Figure 4, more $\mathrm{Y}$ atoms were found around the $\mathrm{D}$ atoms in $\mathrm{Y}_{1.06} \mathrm{Mg}_{0.94} \mathrm{Ni}_{4.00} \mathrm{D}_{3.86}$. The more $\mathrm{Y}$ atoms around the $\mathrm{D}$ atoms resulted in the formation of larger $\mathrm{D}$ atomic sites. The polyhedral volumes of $\mathrm{Y}_{0.81} \mathrm{Mg}_{1.19} \mathrm{Ni}_{4.00} \mathrm{D}_{3.35}$ and $\mathrm{Y}_{1.06} \mathrm{Mg}_{0.94} \mathrm{Ni}_{4.00} \mathrm{D}_{3.86}$ were compared, and the results are listed in Table S12 in the Supporting Information. This would be one of the reasons for higher hydrogen storage capacities of $\mathrm{Y}_{1.06} \mathrm{Mg}_{0.94} \mathrm{Ni}_{4.00} \mathrm{D}_{3.86}$ than $\mathrm{Y}_{0.81} \mathrm{Mg}_{1.19} \mathrm{Ni}_{4.00} \mathrm{D}_{3.35}$. The affinities of $\mathrm{Y}$ and $\mathrm{Mg}$ toward $\mathrm{D}$ are also suspected to affect the hydrogen storage capacity and plateau pressure for hydrogen absorption. Since more Y atoms were located around the D atoms in the crystal structure, the affinity of $\mathrm{Y}$ toward $\mathrm{D}$ contributed to the interactions with the $\mathrm{D}$ atoms more than that of $\mathrm{Mg}$ toward $\mathrm{D}$. Y was guessed to exhibit a qualitatively higher affinity toward hydrogen than $\mathrm{Mg}$ in $\mathrm{YMgNi}_{4}$-based alloys because of the higher thermodynamic stability of the $\mathrm{Y}$ hydrides, ${ }^{19}$ such as $\mathrm{YH}_{2}$ and $\mathrm{YH}_{3}$, compared with that of the $\mathrm{Mg}$ hydride, ${ }^{3}$ e.g., $\mathrm{MgH}_{2}$. Then, the presence of excessive $\mathrm{Y}$ atoms in the $\mathrm{YMgNi}_{4}$-based alloys, where excessive $\mathrm{Y}$ would facilitate a qualitatively stronger interaction of $\mathrm{Y}-\mathrm{H}$ than that of $\mathrm{Mg}-\mathrm{H}$, might result in a lower plateau pressure to form a hydrogen-absorbed phase and cause increased hydrogen storage capacities in the first hydrogen absorption reaction (e.g., $\mathrm{YMgNi}_{4}$-based alloy with $x=0.6$ ). However, the absorbed hydrogen was not released because of the stronger interaction of $\mathrm{Y}-\mathrm{H}$ than that of $\mathrm{Mg}-\mathrm{H}$. Those results suggested that the plateau pressure was tuned by the substitution of the $\mathrm{Mg}$ atoms into the $\mathrm{Y}$ atomic sites in the hydrogen-absorbed phase.

\section{CONCLUSIONS}

$\mathrm{YMgNi}_{4}$-based alloys were synthesized from $(2-x) \mathrm{YNi}_{2}$ and $x \mathrm{MgNi}_{2}(0.6 \leq x \leq 1.2)$ to control the compositional ratios between $\mathrm{Y}$ and $\mathrm{Mg}$. The obtained materials exhibited reversible hydrogen absorption and desorption reactions in which the equilibrium pressure decreased with decreasing amounts of Mg. The hydrogen storage capacities also depended on the quantities of $\mathrm{Mg}$, i.e., lower amounts of $\mathrm{Mg}$ resulted in higher hydrogen storage capacities. However, a $\mathrm{YMgNi}_{4}$-based alloy with $x=0.8$ exhibited the maximum hydrogen capacity $(1.2$ mass \%) because of the formation of a thermodynamically stable hydride phase at $x=0.6$, which exhibited irreversible hydrogen absorption and desorption reactions.

PND experiments in vacuum and at deuterium gas pressure were used to investigate the crystal structures that were formed during hydrogen absorptions in $\mathrm{Y}_{0.81} \mathrm{Mg}_{1.19} \mathrm{Ni}_{4.00}(x=1.0)$ and $\mathrm{Y}_{1.06} \mathrm{Mg}_{0.94} \mathrm{Ni}_{4.00}(x=0.8)$. Formations of $\beta$-phase hydrides (deuterides) with orthorhombic structures, $a=5.0274(2) \AA, b$ $=5.3823(2) \AA, c=7.2853(3) \AA, V=197.13(1) \AA^{3}$, and $Z=2$ in $P_{m n 2}$ (No. 31) in $\mathrm{Y}_{0.81} \mathrm{Mg}_{1.19} \mathrm{Ni}_{4.00} \mathrm{D}_{3.35}$ and $a=5.0407(1)$ $\AA, b=5.4162(2) \AA, c=7.3035(2) \AA, V=199.39(1) \AA^{3}$, and $Z$ $=2$ in $P_{m n 2_{1}}$ (No. 31) in $\mathrm{Y}_{1.06} \mathrm{Mg}_{0.94} \mathrm{Ni}_{4.00} \mathrm{D}_{3.86}$, were observed at $323 \mathrm{~K}$

In this study, the presence of small amounts of the $\mathrm{D}$ atoms with short interatomic D-D distances (1.6 and $1.9 \AA$ ) in deuterium-absorbed phases, $\mathrm{Y}_{0.81} \mathrm{Mg}_{1.19} \mathrm{Ni}_{4.00} \mathrm{D}_{3.35}$ and $\mathrm{Y}_{1.06} \mathrm{Mg}_{0.94} \mathrm{Ni}_{4.00} \mathrm{D}_{3.86}$, which were shorter than the criterion for the minimum interatomic D-D distance (2.1 $\AA$ ), was proposed by neutron diffraction experiments at $D_{2}$ pressure. Notably, the $\mathrm{D}$ atoms with such short interatomic $\mathrm{D}-\mathrm{D}$ distances in the $\beta$-phase hydride of $\mathrm{REMgNi}_{4}(\mathrm{RE}=$ lanthanides) have not been previously reported. Although such D-D atomic pairs with short interatomic distances might not simultaneously exist at each atomic site, the $\mathrm{D}$ atoms with short interatomic $\mathrm{D}-\mathrm{D}$ distances were interestingly found in the same local atomic arrangements as those of the previously described $\gamma$-phase hydride, which exhibited higher hydrogen capacities than the $\beta$ phase hydride.

In the crystal structures, more $\mathrm{Y}$ atoms were located around the $\mathrm{D}$ atoms and caused the formation of larger $\mathrm{D}$ atomic spaces. Moreover, it was guessed that the affinity of the $\mathrm{Y}$ atoms toward D could contribute to the interactions with the $\mathrm{D}$ atoms more than the affinity of $\mathrm{Mg}$ toward $\mathrm{D}$. Similarly, in the case of the $\mathrm{YMgNi}_{4}$-based alloys at $x=0.6$, excessive $\mathrm{Y}$ atoms with qualitatively higher affinities toward hydrogen formed thermodynamically stable hydride phases. However, the equilibrium hydrogen pressure (plateau pressure) could be tuned by the substitution of the $\mathrm{Mg}$ atoms into the $\mathrm{Y}$ atomic sites. Hence, the size of the hydrogen atomic sites as well as the affinity toward hydrogen optimized by the $\mathrm{Y}$ and $\mathrm{Mg}$ ratios around the hydrogen atoms could be keys to controlling their hydrogen storage properties. 


\section{METHODS}

The $\mathrm{YMgNi}_{4}$-based alloys were prepared from powder mixtures of $\mathrm{YNi}_{2}$ and $\mathrm{MgNi}_{2}$ at molar ratios of $2-x: x(x=$ $0.6,0.8,1.0$, and 1.2). $\mathrm{YNi}_{2}$ was prepared by arc-melting of a stoichiometric mixture of Y chips (Sigma-Aldrich, 99.9\%) and $\mathrm{Ni}$ shots (Rare Metallic Co., Ltd., 99.999\%). $\mathrm{MgNi}_{2}$ was obtained by the induction melting of $\mathrm{Mg}$ (Rare Metallic Co., LTD., 99.9\%) and $\mathrm{Ni}$ powders (Rare Metallic Co., LTD., 99.9\%) at a molar ratio of 1.45:2. The PXD patterns of $\mathrm{YNi}_{2}$ and $\mathrm{MgNi}_{2}$ are shown in Figure $\mathrm{S} 10$ in the Supporting Information. $\mathrm{YNi}_{2}$ and $\mathrm{MgNi}_{2}$ were pulverized and mixed at a molar ratio of $2-x: x$. The mixture was pressed into a tablet with a diameter of $6 \mathrm{~mm}$, which was heat-treated at $1073 \mathrm{~K}$ for $24 \mathrm{~h}$ in an Ar atmosphere. Following the first heat treatment, the sample was collected, pulverized, and pressed into a tablet with a diameter of $6 \mathrm{~mm}$. The tablet was further heat-treated at $1123 \mathrm{~K}$ for $24 \mathrm{~h}$ in an Ar atmosphere. All of the products were identified by PXD, which was conducted on a PANalytical X'Pert diffractometer with $\mathrm{Cu} \mathrm{K} \alpha$ radiation (wavelength $\lambda=$ 1.5406 and $1.5444 \AA$ for $\mathrm{K} \alpha 1$ and $\mathrm{K} \alpha 2$, respectively).

The hydrogen storage properties of the products were studied by PCT measurements (PCT-3SPWIN, Suzuki Shokan Co., Ltd.) at $323 \mathrm{~K}$ up to a hydrogen gas pressure of $9 \mathrm{MPa}$. Before the PCT measurements, the samples were heat-treated at $473 \mathrm{~K}$ in a vacuum for $3 \mathrm{~h}$.

SR-PXD and PND were performed on the BL-8A at the Photon Factory (PF), High Energy Accelerator Research Organization (KEK) in Japan and the NOVA (BL21) at the Material and Life Science Experimental Facility (MLF) of the Japan Proton Accelerator Research Complex (J-PARC) in Japan, respectively. For SR-PXD, the samples were placed in a Lindemann glass capillary with an outside diameter of $0.3 \mathrm{~mm}$ and thickness of $0.01 \mathrm{~mm}$. The measurement was conducted in an $\mathrm{Ar}$ atmosphere, and the data were collected at room temperature. The wavelength of $0.775777(3) \AA$ was obtained based on the $\mathrm{CeO}_{2}$ powder data. In the PND experiments, the samples were focused on $x=1.0$ and 1.2 since $x=1.0$ was the basis of this study, whereas $x=1.2$ exhibited the highest hydrogen content. The samples were placed in a V sample container with an outside diameter of $10.80 \mathrm{~mm}$ and thickness of $1.5 \mathrm{~mm}$. The samples were heat-treated at $423 \mathrm{~K}$ in vacuum for $3 \mathrm{~h}$ to initiate the hydrogen absorption reaction. Following heat treatment, the PND data were collected at $323 \mathrm{~K}$ under vacuum and deuterium gas pressure.

The indexing programs, TREOR $97^{20}$ and PIRUM, ${ }^{21}$ and the Rietveld refinement program, GSAS with the graphical interface, EXPGUI (version 1.80) ${ }^{22}$ were used for the investigations of the crystal structure obtained from the SRPXD and PND data. In the Rietveld method, the pseudo-Voigt peak shape function with the Finger-Cox-Jephcoat asymmetry correction ${ }^{23}$ and TOF profile function extension of a profile function developed by Von Dreele et al. ${ }^{24}$ were used for SRPXD and PND, respectively. The background was modeled using the Chebyschev polynomial function model in GSAS. The isotropic temperature-displacement parameters were used for all elements.

All of the samples were handled in Ar- or He-gas-filled gloveboxes with dew points of $<183 \mathrm{~K}$ and $<1 \mathrm{ppm}$ of $\mathrm{O}_{2}$ to prevent (hydro-)oxidation.

\section{ASSOCIATED CONTENT}

\section{SI Supporting Information}

The Supporting Information is available free of charge at https://pubs.acs.org/doi/10.1021/acsomega.0c04535.

X-ray diffraction patterns (Figures S5 and S10); Rietveld refinement fits of SR-PXD and PND (Figure S1-S4, S7-S9); PCT curves (Figure S6); crystallographic parameters (Tables S1-S10); interatomic distances (Table S11); and comparisons of polyhedral volumes for D atomic sites (Table S12) (PDF)

\section{AUTHOR INFORMATION}

\section{Corresponding Author}

Toyoto Sato - Institute for Materials Research, Tohoku University, Miyagi 980-8577, Japan; ○ orcid.org/00000002-0527-1235; Email: toyoto@imr.tohoku.ac.jp

\section{Authors}

Tomohiro Mochizuki - Institute for Materials Research, Tohoku University, Miyagi 980-8577, Japan

Kazutaka Ikeda - Institute of Materials Structure Science, High Energy Accelerator Research Organization (KEK), Tsukuba 305-0801, Japan

Takashi Honda - Institute of Materials Structure Science, High Energy Accelerator Research Organization (KEK), Tsukuba 305-0801, Japan; 이 orcid.org/0000-0003-41218957

Toshiya Otomo - Institute of Materials Structure Science, High Energy Accelerator Research Organization (KEK), Tsukuba 305-0801, Japan

Hajime Sagayama - Institute of Materials Structure Science, High Energy Accelerator Research Organization (KEK), Tsukuba 305-0801, Japan

Heena Yang - Institute of Chemical Sciences and Engineering, Basic Science Faculty, École polytechnique fédérale de Lausanne (EPFL) Valais/Wallis, CH-1951 Sion, Switzerland; Empa Materials Science and Technology, 8600 Dübendorf, Switzerland; (1) orcid.org/0000-0002-61139474

Wen Luo - Institute of Chemical Sciences and Engineering, Basic Science Faculty, École polytechnique fédérale de Lausanne (EPFL) Valais/Wallis, CH-1951 Sion, Switzerland; Empa Materials Science and Technology, 8600 Dübendorf, Switzerland; (1) orcid.org/0000-0003-42506168

Loris Lombardo - Institute of Chemical Sciences and Engineering, Basic Science Faculty, École polytechnique fédérale de Lausanne (EPFL) Valais/Wallis, CH-1951 Sion, Switzerland; Empa Materials Science and Technology, 8600 Dübendorf, Switzerland

Andreas Züttel - Institute of Chemical Sciences and Engineering, Basic Science Faculty, École polytechnique fédérale de Lausanne (EPFL) Valais/Wallis, CH-1951 Sion, Switzerland; Empa Materials Science and Technology, 8600 Dübendorf, Switzerland

Shigeyuki Takagi - Institute for Materials Research, Tohoku University, Miyagi 980-8577, Japan

Tatsuoki Kono - Institute for Materials Research, Tohoku University, Miyagi 980-8577, Japan

Shin-ichi Orimo - Institute for Materials Research and WPIAdvanced Institute for Materials Research (AIMR), Tohoku University, Miyagi 980-8577, Japan 
Complete contact information is available at:

https://pubs.acs.org/10.1021/acsomega.0c04535

\section{Notes}

The authors declare no competing financial interest.

\section{ACKNOWLEDGMENTS}

This research was supported by JST SICORP (JPMJSC 1802) and MEXT/JSPS KAKENHI (JP18H05513, JP18H05518, 19K05051). Synchrotron powder X-ray and neutron diffraction were approved by the Photon Factory Program Advisory Committee (Proposal No. 2019G572) and the Neutron Science Proposal Review Committee of J-PARC MLF (Proposal Nos. 2019A0068 and 2019B0390).

\section{REFERENCES}

(1) Schlapbach, L.; Züttel, A. Hydrogen-Storage Materials for Mobile Applications. Nature 2001, 414, 353-358.

(2) Züttel, A. Materials for Hydrogen Storage. Mater. Today 2003, 6, 24-33.

(3) Crivello, J.-C.; Dam, B.; Denys, R. V.; Dornheim, M.; Grant, D. M.; Huot, J.; Jensen, T. R.; Jongh de, P.; Latroche, M.; Milanese, C.; Milčius, D.; Walker, G. S.; Webb, C. J.; Zlotea, C.; Yartys, V. A. Review of Magnesium Hydride-Based Materials: Development and Optimisation. Appl. Phys. A: Mater. Sci. Process. 2016, 122, No. 97.

(4) Aono, K.; Orimo, S.; Fujii, H. Structural and Hydriding Properties of $\mathrm{MgYNi}_{4}$ : A new intermetallic compound with $\mathrm{C} 15 \mathrm{~b}-$ type Laves phase structure. J. Alloys Compd. 2000, 309, L1-L4.

(5) Guénée, L.; Favre-Nicolin, V.; Yvon, K. Synthesis, Crystal Structure and Hydrogenation Properties of the Ternary Compounds $\mathrm{LaNi}_{4} \mathrm{Mg}$ and $\mathrm{NdNi}_{4} \mathrm{Mg}$. J. Alloys Compd. 2003, 348, 129-137.

(6) Chotard, J.-N.; Sheptyakov, D.; Yvon, K. Hydrogen Induced Site Depopulation in the $\mathrm{LaMgNi}_{4}-$ Hydrogen System. Z. Kristallogr. 2008, 223, 690-696.

(7) Terashita, N.; Akiba, E. Hydriding Properties of $\left(\mathrm{Mg}_{1-x} \mathrm{M}_{x}\right) \mathrm{Ni}_{2}$ C15-Type Laves Phase Alloys. Mater. Trans., JIM 2006, 47, 18901893.

(8) Sakaki, K.; Terashita, N.; Tsunokake, S.; Nakamura, Y.; Akiba, E. In Situ X-ray Diffraction Study of Phase Transformation of $\mathrm{Mg}_{2-x} \mathrm{Pr}_{x} \mathrm{Ni}_{4}$ during Hydrogenation and Dehydrogenation $(x=0.6$ and 1.0). J. Phys. Chem. C 2012, 116, 1401-1407.

(9) Sakaki, K.; Terashita, N.; Tsunokake, S.; Nakamura, Y.; Akiba, E. Effect of Rare Earth Elements and Alloy Composition on Hydrogenation Properties and Crystal Structures of Hydrides in $\mathrm{Mg}_{2-x} \mathrm{RE}_{x} \mathrm{Ni}_{4}$. J. Phys. Chem. C 2012, 116, 19156-19163.

(10) Sakaki, K.; Terashita, N.; Kim, H.; Proffen, T.; Majzoub, E. H.; Tsunokake, S.; Nakamura, Y.; Akiba, E. Crystal Structure and Local Structure of $\mathrm{Mg}_{2-x} \mathrm{Pr}_{x} \mathrm{Ni}_{4}(x=0.6$ and 1.0) Deuteride Using in Situ Neutron Total Scattering. Inorg. Chem. 2013, 52, 7010-7019.

(11) Shtender, V. V.; Denys, R. V.; Paul-Boncour, V.; Riabov, A. B.; Zavaliy, I. Yu. Hydrogenation Properties and Crystal Structure of $\mathrm{YMgT}_{4}(T=\mathrm{Co}, \mathrm{Ni}, \mathrm{Cu})$ Compounds. J. Alloys Compd. 2014, 603, $7-13$.

(12) Kadir, K.; Noréus, D.; Yamashita, I. Structural Determination of $\mathrm{AMgNi}_{4}$ (Where $\mathrm{A}=\mathrm{Ca}, \mathrm{La}, \mathrm{Ce}, \mathrm{Pr}, \mathrm{Nd}$ and $\mathrm{Y}$ ) in the AuBe $\mathrm{A}_{5}$ Type Structure. J. Alloys Compd. 2002, 345, 140-143.

(13) Aoki, K.; Masumoto, T. Solid State Amorphization of Intermetallic Compounds by Hydrogenation. J. Alloys Compd. 1993, 194, 251-261.

(14) Murray, J. J.; Post, M. L.; Taylor, J. B. The Thermodynamics of The $\mathrm{LaNi}_{5}-\mathrm{H}_{2}$ System by Differential Heat Flow Calorimetry I: Techniques; The $\alpha+\beta$ Two-Phase Region. J. Less-Common Met. 1981, 80, 201-209.

(15) Switendick, A. C. Band Structure Calculations for Metal Hydrogen Systems. Z. Phys. Chem. 1979, 117, 89-112.

(16) Yartys, V. A.; Denys, R. D.; Hauback, B. C.; Fjellvåg, H.; Bulyk, I. I.; Riabov, A. B.; Kalychak, Y. M. Short Hydrogen-Hydrogen
Separations in Novel Intermetallic Hydrides, $\mathrm{RE}_{3} \mathrm{Ni}_{3} \mathrm{In}_{3} \mathrm{D}_{4}(\mathrm{RE}=\mathrm{La}$, Ce and Nd). J. Alloys Compd. 2002, 330-332, 132-140.

(17) Vajeeston, P.; Ravindran, P.; Vidya, R.; Kjekshus, A.; Fjellvåg, H.; Yartys, V. A. Short Hydrogen-Hydrogen Separation in $\mathrm{RNiInH}_{1.333}(\mathrm{R}=\mathrm{La}, \mathrm{Ce}, \mathrm{Nd})$. Phys. Rev. B 2003, 67, No. 014101.

(18) Borgschulte, A.; Terreni, J.; Billeter, E.; Daemen, L.; Cheng, Y.; Pandey, A.; Łodziana, Z.; Hemley, R. J.; Ramirez-Cuesta, A. J. Inelastic Neutron Scattering Evidence for Anomalous $\mathrm{H}-\mathrm{H}$ Distances in Metal Hydrides. Proc. Natl. Acad. Sci. U.S.A. 2020, 117, 40214026.

(19) Yannopoulos, L. N.; Edwards, R. K.; Wahlbeck, P. G. The Thermodynamics of the Yttrium-Hydrogen System. J. Phys. Chem. A 1965, 69, 2510-2515.

(20) Werner, P.-E.; Eriksson, L.; Westdahl, M. TREOR, A SemiExhaustive Trial-and-Error Powder Indexing Program for All Symmetries. J. Appl. Crystallogr. 1985, 18, 367-370.

(21) Werner, P.-E. A Fortran Program for Least-Squares Refinement of Crystal-Structure Cell Dimensions. Ark. Kemi 1970, 31, 513-516.

(22) Toby, B. H. EXPGUI, A Graphical User Interface for GSAS. J. Appl. Crystallogr. 2001, 34, 210-213.

(23) Thompson, P.; Cox, D. E.; Hastings, J. B. Rietveld Refinement of Deby-Scherrer Synchrotron X-ray Data from $\mathrm{Al}_{2} \mathrm{O}_{3}$. J. Appl. Crystallogr. 1987, 20, 79-83.

(24) Von Dreele, R. B.; Jorgensen, J. D.; Windsor, C. G. Rietveld Refinement with Spallation Neutron Powder Diffraction Data. J. Appl. Crystallogr. 1982, 15, 581-589. 